\title{
Plenitudinous Russellianism, 'That'-Clauses, and the Principle of Substitutivity
}

\author{
SEYED N. MOUSAVIAN (D) Institute for Research in Fundamental Sciences \\ (IPM), Iran \\ University of Gothenburg, Sweden
}

ABSTRACT: Recently, in a series of papers, Joshua Spencer has introduced, defended, and developed a modified version of Neo-Russellianism (NR), namely Plenitudinous Russellianism (PR), according to which there are structurally identical but numerically distinct singular Russellian propositions (SRPS). PR claims to provide novel semantic solutions to all the major problems that NR faces with no radical revision in NR. In this paper, I introduce a semantic puzzle for PR: the view leads to the violation of the principle of substitutivity of co-referential proper names within simple (predicative) 'that'-clauses (PS1). I consider different responses to my argument, and show that none of them is fully satisfactory for the Russellian. I conclude that PR needs to depart from NR more radically.

RÉSUMÉ : Récemment, Joshua Spencer a publié une série d'articles où il expose, défend et développe une version modifiée du Néo-Russellianisme (NR), appelée Russellianisme de plénitude (Plenitudinous Russellianism) (PR), selon laquelle il y a des propositions Russelliennes singulières (SRP) structurellement identiques mais numériquement distinctes. Ce Russellianisme de plénitude prétend apporter de nouvelles solutions sémantiques à tous les problèmes majeurs auxquels le NR se confronte, sans pour autant procéder à une révision radicale du NR. Dans cet article, je mettrai le PR face à un casse-tête : cette vision

Dialogue 60 (2021), 121-144

(C) The Author(s), 2020. Published by Cambridge University Press on behalf of the Canadian Philosophical Association/l'Association canadienne de philosophie. This is an Open Access article, distributed under the terms of the Creative Commons Attribution-NonCommercial-NoDerivatives licence (http://creativecommons.org/ licenses/by-nc-nd/4.0/), which permits non-commercial re-use, distribution, and reproduction in any medium, provided the original work is unaltered and is properly cited. The written permission of Cambridge University Press must be obtained for commercial re-use or in order to create a derivative work. doi:10.1017/S0012217320000347 
mène à la violation du principe de substitution des noms propres co-référentiels au sein des subordonnées complétives (conjonctives) simples (PS1). Je tâcherai de considérer différentes réponses à mon argument et de montrer qu'aucune d'entre elles n'est pleinement satisfaisante pour un Russellien. Je vais conclure que le PR devrait s'écarter plus radicalement du NR.

Keywords: Russellianism, Millianism, Plenitudinous Russellianism, 'That'-Clauses, Principle of Substitutivity, Proposition

\section{Introduction}

Consider:

(1) The semantic content of a simple proper name $(\lceil\mathrm{N}\rceil)$ is the (particular) object or individual to which it semantically refers (Millianism). ${ }^{1}$

(2) The semantic content of a simple predicate ( $\lceil$ is $\mathrm{F}\rceil$ ) is the property or relation to which it semantically refers (or expressed by the predicate).

(3) The semantic content of a simple atomic sentence ( $\lceil\mathrm{N}$ is $\mathrm{F}\rceil)$ is a singular Russellian proposition (SRP) semantically expressed by the sentence (Russellianism).

(4) The SRP semantically expressed by a simple atomic sentence ( $\lceil\mathrm{N}$ is $\mathrm{F}\rceil$ ) is uniquely determined by the semantic content of the proper name and that of the simple predicate (Uniqueness).

(5) The semantic content of a simple (predicative) 'that'-clause (「that $\mathrm{N}$ is $\mathrm{F}\rceil)$ is the SRP semantically expressed by the simple atomic sentence ( $\lceil\mathrm{N}$ is $\mathrm{F}\rceil$ ) embedded in the 'that'-clause. ${ }^{2}$

Call the conjunction of (1)-(5) 'Neo-Russellianism' (NR). ${ }^{3}$ NR has been defended by many, e.g., Nathan Salmon, ${ }^{4}$ Scott Soames, ${ }^{5}$

1 By a 'simple proper name,' 'simple predicate,' or 'simple atomic sentence,' I mean a particular use of each of them in English.

2 The 'that'-clause ( $\lceil$ that $\mathrm{N}$ is $\mathrm{F}\rceil$ ) semantically refers to, and does not express, the SRP semantically expressed by the simple atomic sentence ( $[\mathrm{N}$ is $\mathrm{F}\rceil$ ) embedded in the 'that'-clause.

3 NR, also called 'Naive Russellianism,' typically includes the following thesis:

(6) The semantic content of a simple propositional attitude verb like 'believes' is a binary relation like believing (also represented as BELIEVES).

See Braun, "Cognitive Significance, Attitude Ascriptions, and Ways of Believing," for instance. Since I will discuss neither attitude verbs nor 'that'-clauses in modal, epistemic, or otherwise intensional contexts, I do not need to add (6) to my characterization of NR.

4 Salmon, Frege's Puzzle and Metaphysics, Mathematics, and Meaning.

5 Soames, Beyond Rigidity. 
David Braun, ${ }^{6}$ and Fred Adams et al., ${ }^{7}$ and is claimed to be the simplest and most successful semantic theory available for proper names, simple predicates, simple atomic sentences, and simple (predicative) 'that'-clauses. NR, however, faces significant problems raised by empty names, ${ }^{8}$ Frege's Puzzle of Identity, and Frege's Puzzle of Cognitive Value, ${ }^{9}$ among other problems. The classic versions of NR, developed by Salmon, Soames, Braun, and Adams et al., do not provide 'semantic' solutions to these problems; rather, they employ pragmatic or psychological explanations to explain away anti-Neo-Russellian intuitions. However, it has been claimed, ${ }^{10}$ the problems are 'semantic'; the anti-Neo-Russellian intuitions are resistant to the change in the speaker's specific intention and speaker's psychology. This suggests that the problems relate to what one may call 'semantic content,' broadly construed.

Some have attempted to solve some of these problems, mostly the ones that relate to 'structure,' by revising the notion of 'structure' employed in the characterization of the Russellian propositions (RPs). One way to do this, following Kit Fine, ${ }^{11}$ is to use "representing as the same" or "coordination, at the level both of syntax and of semantics." 12 Another way to do this is to assume that propositions" "structures are identical to the syntactic structures of the sentences that express them." 13 Such views allow more fine-grained individuation of RPs than the classic versions of NR do. However, they do not attempt to provide semantic solutions to all the major problems that NR encounters, e.g., the problems raised by empty names and the apparent difference in meaning between 'Hesperus is a planet' and 'Phosphorus is a planet.'

6 Braun, "Russellianism and Explanation," "Russellianism and Predication," and "Cognitive Significance, Attitude Ascriptions, and Ways of Believing."

7 See Adams and Dietrich, "What's in a(n Empty) Name?," and Adams and Fuller, "Empty Names and Pragmatic Implicatures."

8 See Everett "Empty Names and 'Gappy' Propositions," for a criticism of NR, Braun "Empty Names, Fictional Names, Mythical Names," for a reply to Everett, and Mousavian "Gappy Propositions?" for a reply to Braun, and Everett, The Nonexistent, for a recent discussion of the literature.

9 On the distinction between the last two problems see, for example, Spencer, "Plenitudinous Russellianism."

10 See, for example, Mousavian, "Pragmatics of No Reference."

11 Fine, Semantic Relationalism.

12 Fine, Semantic Relationalism, 31.

13 King, "Designating propositions," 341. King has slightly revised his view from The Nature and Structure of Content, to King, Soames, and Speaks, New Thinking about Propositions. The core of the view, however, remains the same. For criticism of King, see Hodgson, "Why We Should Not Identify Sentence Structure with Propositional Structure," "The Structure of Content Is Not Transparent." 
Some others, e.g., Soames ${ }^{14}$ and Peter Hanks, ${ }^{15}$ have departed from NR altogether by identifying propositions as the types of some mental acts, i.e., predications. The differences among these views aside, they also lead to a new conception of 'structure,' according to which "the structure of a proposition is provided by the truth-condition-determining cognitive operations performed on its constituents by an agent who entertains it."16 These "cognitive structures" introduce "cognitive propositions" that can solve more of the above-mentioned problems for NR. Nonetheless, the problems raised by empty names will remain. ${ }^{17}$ Moreover, for Russellians, the mental act theory of propositions seems to be too radical a departure from NR.

Joshua Spencer, in a series of papers, ${ }^{18}$ has introduced, defended, and developed a slightly modified version of NR, namely Plenitudinous Russellianism (PR) that (i) does not modify the Russellian notion of 'structure,' (ii) is (allegedly) faithful to all the theses of NR except one, i.e., (4) (Uniqueness), (iii) provides 'semantic' solutions to the problems raised by empty names, ${ }^{19}$ Frege's Puzzle of Identity and Frege's Puzzle of Cognitive Value, ${ }^{20}$ and (iv) creates surplus theoretical value, e.g., PR promises to block Timothy Williamson's argument to Necessitism (namely "it is necessary what there is"). ${ }^{21}$ If PR can deliver

14 Soames, "Cognitive Propositions," Rethinking Language, Mind, and Meaning, and "Propositions as Cognitive Acts."

Hanks, "Structured Propositions as Types" and Propositional Content.

16 Soames, "Cognitive Propositions," 119.

17 Soames, Rethinking Language, Mind, and Meaning, 224-234.

18 Spencer, "Unnecessary Existents," "The Problem of Empty Names and Russellian Plenitude," and "Plenitudinous Russellianism."

Spencer, "The Problem of Empty Names and Russellian Plenitude."

20 Spencer, "Plenitudinous Russellianism."

21 Williamson, Modal Logic as Metaphysics, 2. Here is an argument for Necessitism (Spencer, "Unnecessary Existents," 766):

(ARG 1)

(1.1) Necessarily, if o does not exist, then the proposition that o does not exist is true.

(1.2) Necessarily, if the proposition that o does not exist is true, then the proposition that o does not exist exists.

(1.3) Necessarily, if the proposition that o does not exist exists, then o exists. Therefore,

(1.4) Necessarily, if o does not exist, then o exists.

(Timothy Williamson's ("Necessary Existents") original version of the argument uses 'I' instead of 'o.' To avoid problems associated with the semantics of 'I,' I have used the above formulation.) Spencer ("Unnecessary Existents," 768) rejects the thesis that "propositions have their constituents essentially." Consequently, Spencer ("Unnecessary Existents," 769) rejects (1.3). According to him, the proposition 
what it promises, it does something that no other Neo-Russellian view does: it solves all the major problems that NR faces with no radical revision in NR.

Here, I shall argue that this is not the case. PR is not a stable position: it leads to the violation of the principle of substitutivity of co-referential proper names within simple (predicative) 'that'-clauses (PS1) and/or the principle of substitutivity of co-referential proper names within simple (predicative) sentences (PS2). To avoid the puzzle, the proponent of PR might reject PS1 and PS2, or their applications in (ARG 2)-(ARG 4). Accordingly, one might treat 'that'clauses as 'intensional contexts' in which co-referential proper names may not be substitutable salve veritate. This reply seems to push PR toward Fregeanism, so far as 'that'-clauses are at stake. The Russellian would not find this reply promising for different reasons, e.g., the consensus to preserve both PS1 and PS2 not only in the extensional contexts but also in the context of modal operators and attitude verbs. Alternatively, to save PS1 and PS2, the proponent of PR might try to revise the semantics of 'that'-clauses by further revising NR (and PR). I will consider two such possible revisions and show that either the puzzle will resurge or the attempted solution is ad hoc and undermines a main motivation for PR. Either way, PR needs to depart from NR more radically.

\section{Plenitudinous Russellianism}

Spencer has introduced, defended, and developed PR. ${ }^{22}$ The view is committed to (1)-(3) above, in the characterization of NR, and consistent with (5). PR, however, rejects (4) (Uniqueness):

Plenitudinous Russellianism is distinguished from Traditional Russellianism by two theses. First, that [PR1] there are distinct propositions that have exactly the same constituents playing exactly the same roles. And, second, [PR2] the proposition expressed by a simple declarative sentence is not simply determined by the semantic contents of the subject and predicate of that sentence but also by reference relations. ${ }^{23}$

PR1 is the thesis that there are structurally identical but numerically distinct SRPs. PR2 implies the negation of (4). According to PR2, "reference relations," over and above referents (or constituents), also contribute to the determination of the proposition expressed by a simple atomic sentence. I will explain.

(continued)

that o does not exist may exist even if o does not exist. Hence, Spencer rejects the conclusion of (ARG 1), namely (1.4). For further discussion, see Spencer, "Unnecessary Existents."

22 See note 18 above.

23 Spencer, "The Problem of Empty Names and Russellian Plenitude," 390. 
Consider the definition of 'semantic means of reference' first: "Let's say that $\mathrm{m}[$ or $\mathrm{M}]$ is the means by which $N[($ or P $)]$ refers to o (or $\mathrm{F})=\mathrm{df} \mathrm{m}[$ or $\mathrm{M}]$ is a particular chain of causal or historical explanations that leads from o (or F) to the introduction of $\mathrm{N}\left[(\right.$ or P) $]$ (or the use of $\mathrm{N}\left[\left(\right.\right.$ or P)]). ${ }^{, 24}$ Then, the existence condition (EC) for a simple atomic SRP is introduced as follows:

[EC] For every possible means by which an expression can refer to an entity, $x$, and every possible means by which a predicate can refer to a property, $\mathrm{F}$, there is a corresponding proposition the subject-like role of which is uniquely associated with that first means and the predicate-like role of which is uniquely associated with the second means and that contains $x$ playing the subject-like role and that contains F playing the predicate-like role. $^{25}$

Since there is a plenitude of semantic means of reference $(\mathrm{m})$ to a particular object (o) and a plenitude of semantic means of reference (M) to a specific property (F), EC implies that there is a plenitude of SRPs having o (playing the subject-like role) and F (playing the predicate-like role). This, in turn, implies that a simple atomic proposition is not individuated by its propositional structure, constituents, and the roles that the constituents play. Following Spencer, let's call the propositions that have the same propositional structure, constituents, and semantic roles that the constituents play 'structurally identical.' According to PR, there are structurally identical but numerically distinct SRPs. Thus, PR1.

The identity condition (IC) for simple atomic SRPs can be given as follows:

[IC] For any proposition $\mathrm{p}$ and any proposition $\mathrm{q}, \mathrm{p}$ is structurally identical to $\mathrm{q}$ and for each role, $R$, the means of reference associated with $R$ in $p$ is the same means of reference as the means of reference associated with $\mathrm{R}$ in $\mathrm{q}$ iff $\mathrm{p}$ is numerically identical to $\mathrm{q}^{26}$

IC allows means of reference to contribute to the identity conditions for SRPs. EC and IC, however, do not let means of reference get into the nature of SRPs. More particularly, and pace all other revisionary accounts of NR, the notion of 'structure' employed in the characterization of SRPs, according to PR, is the same as the notion of 'structure' employed in the classic versions of NR.

The following example may help. Consider (6) and (7), uttered at the time of Mark Twain:

(6) Mark Twain is an author.

(7) Samuel Clemens is an author.

\footnotetext{
24 Spencer, "Plenitudinous Russellianism."

25 Spencer, "Plenitudinous Russellianism."

26 Spencer, "Plenitudinous Russellianism."
} 
Given that the means of reference by which 'Mark Twain' refers to Mark Twain is different from the means of reference by which 'Samuel Clemens' refers to Mark Twain, by EC and IC, it follows that (6) and (7) semantically express two structurally identical but numerically distinct SRPs. Let us represent these propositions respectively by:

(6p) $<$ Mark Twain, being an author $>_{1}$

(7p) $<$ Mark Twain, being an author $>_{2}$

Note that (6p) and (7p) are both singular propositions (thus, their constituents are individuals and properties). They differ in virtue of different means of reference to Mark Twain. Spencer is keen to add that "the subscript is no more a constituent of the proposition expressed than the comma or the pointy brackets themselves." ${ }^{27}$ Thus, (6p) and (7p) are the same so long as their propositional structures, constituents, or the roles that their constituents play are concerned. They differ in virtue of something 'external' to them and this is enough to give them different functions and, thus, different cognitive profiles. $^{28}$

It is not hard to see how PR can solve Frege's Puzzle of Identity and Frege's Puzzle of Cognitive Value. ${ }^{29}$ It suffices to mention that according to PR and assuming that the semantic means of reference by which 'Hesperus' refers to Venus is different from the semantic means of reference by which 'Phosphorus' refers to Venus, (8) and (9), namely:

(8) Hesperus is Hesperus.

(9) Hesperus is Phosphorus.

27 Spencer, "The Problem of Empty Names and Russellian Plenitude," 398.

28 For example, consider this:

Although the proposition that Samuel Clemens is an author if Mark Twain is an author has the same function, insofar as it is a proposition, as the proposition that Mark Twain is an author if Mark Twain is an author, it has a different function insofar as it is the particular proposition that it is. The proposition that Samuel Clemens is an author if Mark Twain is an author functions as the content of belief when that belief is action-guiding in a particular way; when, for example, it guides one to affirm the sentence 'Samuel Clemens is an author if Mark Twain is an author' or when it guides one to believe that Samuel Clemens is an author when one already believes that Mark Twain is an author. The proposition that Mark Twain is an author if Mark Twain is an author doesn't seem to perform the same functions. (Spencer, "Plenitudinous Russellianism.")

29 See Spencer, "Plenitudinous Russellianism." 
semantically express two structurally identical but numerically distinct SRPs. These propositions can respectively be represented by:

$$
\begin{aligned}
& (8 p)<\text { Hesperus, }=\text {, Hesperus }>_{1} \\
& (9 p)<\text { Hesperus, }=, \text { Hesperus }>_{1,2}
\end{aligned}
$$

Index 1 , is supposed to record the impact of the semantic means of reference associated with 'Hesperus' on the semantic content of (8) and index 2 is supposed to record the impact of the semantic means of reference associated with 'Phosphorus' on the semantic content of (9), because (9) contains an occurrence of 'Hesperus' as well, index 1 does not disappear from (9p). Therefore, Hammurabi may reasonably believe (8p) and not believe (9p) and this can be explained by the semantic fact that $(8 p)$ and $(9 p)$ are only structurally identical but numerically distinct SRPs.

PR, furthermore, rejects the thesis that "propositions have their constituents essentially"30 and accepts gappy propositions (GPs). ${ }^{31}$ As a result, PR is able to provide a 'semantic' solution to one of the most recalcitrant problems raised by empty names for NR, namely the problem of apparent difference in meaning between sentences like:

(10) Vulcan is a planet.

(11) Sherlock Holmes is a planet.

Here is the problem: given that 'Vulcan' and 'Sherlock Holmes' are genuinely empty names, i.e., they have no semantic referents, and assuming NR and that (10) and (11) express GPs, it follows that they express the same GP. Let us represent this GP by:

$$
(10 / 11)<\ldots \text {, being a planet }>
$$

Thus, (10) and (11) have the same semantic content. Therefore, (10) and (11) should say the same thing, semantically speaking. However, there is a strong intuition that (10) and (11) have different meanings. ${ }^{32}$

Neo-Russellians, typically, attempt to resolve the tension by explaining (or explaining away) the intuition that (10) and (11) have different meanings by appealing to pragmatics or psychology. In other words, the general Russellian strategy is to 'divorce' (intuitive) meaning from semantic content by means of pragmatic or psychological explanations. PR, in contrast, can easily introduce

\footnotetext{
30 Spencer, "Unnecessary Existents," 768.

31 See note 8 above.

32 For further discussion, see Everett, "Empty Names and 'Gappy' Propositions."
} 
two structurally identical but numerically distinct GPs such that one is the semantic content of (10) and the other is the semantic content of (11). Suppose that the means of attempted reference associated with 'Vulcan' is different from the means of attempted reference associated with 'Sherlock Holmes. ${ }^{33}$ By EC and IC, it follows that there are two structurally identical but numerically distinct GPs, which can respectively be represented by:

$(10 \mathrm{gp})<\ldots$, being a planet $>_{1}$

$$
(11 \mathrm{gp})<\ldots \text {, being a planet }>_{2}
$$

According to PR, one may conclude, (10) semantically expresses (10gp) and (11) semantically expresses (11gp). Again, indices, like commas and brackets, are not amongst the constituents of the GPs (10gp) and (11gp). If so, then that (10) and (11) have different meanings can be explained by the 'semantic fact' that (10) and (11) semantically express different propositions.

\section{A Prima Facie Metaphysical Problem}

So far, so good. Here, however, is a metaphysical concern regarding the individuation of SRPs. Consider (6p) and (7p) again:

(6p) $<$ Mark Twain, being an author $>_{1}$

(7p) $<$ Mark Twain, being an author $>_{2}$

Given PR, (6p) and (7p) only differ externally; nothing internal to them plays any role in their non-identity. They differ from each other in virtue of some facts, namely the semantic facts involving association with specific means of reference, external to the inner nature of these propositions. However, it might be claimed, if (6p) and (7p) differ externally, then they also differ internally, so to speak - otherwise the claim being made is that one and the same thing does and does not have such-and-such external relation. But, on PR, (6p) and (7p) do not differ internally. Therefore, PR is false.

The above concern is based, among other things, on the assumption that if two objects differ externally, then they differ internally. Consider the contraposition of this assumption: "if two objects do not differ internally, then they do not differ externally." Claims about identity raise thorny issues. The least is that the assumption or its contraposition are not held unequivocally. For example, if one assumes that 'constitution' is not 'identity,' then the reconstructed

33 Here, for the sake of argument, I assume that means of attempted reference (in cases of reference failure) can play the same role in individuation of GPs as means of reference (in cases of successful reference) in individuation of standard Russellian propositions. 
ship of Theseus is not the original ship of Theseus. The two, however, are internally identical; they have the same parts and the same form (given an appropriate form of endurantism about their parts, for example). Assuming that the original ship of Theseus and the reconstructed ship differ in some external properties, e.g., their locations, it follows that there are two objects that do not differ internally but they do differ externally. ${ }^{34}$

Admittedly, constitution may well be identity ${ }^{35}$ and the above argument by analogy may not help PR. Having said that, how to provide a metaphysical ground for PR is one thing and whether the view is semantically adequate is another. Here, I put the metaphysical problems that PR may raise aside and focus on the view's semantic adequacy. In particular, I will try to derive one of the odd semantic consequences of PR.

\section{A Semantic Puzzle}

Recall:

(5) The semantic content of a simple (predicative) 'that'-clause (「that $\mathrm{N}$ is $\mathrm{F}\rceil)$ is the SRP semantically expressed by the simple atomic sentence ( $\lceil\mathrm{N}$ is $\mathrm{F}\rceil$ ) embedded in the 'that'-clause.

Consider the following two 'that'-clauses:

(6') That Mark Twain is an author

$\left(7^{\prime}\right)$ That Samuel Clemens is an author

Given PR, (6) and (7) express structurally identical but numerically distinct SRPs. Assuming (5), it follows that $\left(6^{\prime}\right)$ and ( $\left.7^{\prime}\right)$ semantically refer to two different SRPs. ${ }^{36}$ Then, consider the following instance of the application of the principle of substitutivity of co-referential proper names within a simple (predicative) 'that'-clause, in an extensional context:

\section{(ARG 2)}

(2.1) That Mark Twain is an author is that Mark Twain is an author.

(2.2) Mark Twain is Samuel Clemens.

34 For a view along this line, but not in a semantic context, see Baker, Persons and Bodies.

35 See, for instance, Noonan, "Constitution Is Identity."

36 If the details of this particular example are not satisfying, take your own favourite co-(directly)referential singular terms. 
(2.3) That Mark Twain is an author is that Samuel Clemens is an author.

(2.1) expresses a simple (semantic) identity fact, namely (6p), the proposition, is identical to (6p). The semantic content of (2.1), then, can be represented by:

(2.1p) $<<$ Mark Twain, being an author $>_{1},=$, $<$ Mark Twain, being an author $>_{1}>$

(2.2.) expresses another simple identity fact, namely that Mark Twain, the individual, is identical to Mark Twain. Assuming PR, and that the semantic means of reference by which 'Mark Twain' refers to Mark twain is different from the semantic means of reference by which 'Samuel Clemens' refers to Mark Twain, the semantic content of (2.2), can be represented by:

$$
(2.2 \mathrm{p})<\text { Mark Twain, }=, \text { Mark Twain }>_{1,2}
$$

The two indices, 1 and 2, are supposed to record the impact of the means of reference associated with 'Mark Twain' and that associated with 'Samuel Clemens' on the semantic content of (2.2).

The rule that legitimizes the move from (2.1) and (2.2) to (2.3) is the principle of substitutivity of co-referential proper names within a simple (predicative) 'that'-clause, in an extensional context (PS1). Let me formulate PS1 explicitly as follows:

(PS1) If ' $a$ ' and 'b' are co-referential proper names and 'a' occurs in a simple predicative 'that'-clause, in an extensional context, substituting one (or more) occurrence (s) of 'a' with 'b' results in a 'that'-clause with the same semantic reference.

By 'a simple predicative 'that'-clause,' in PS1, I mean a 'that'-clause in which an atomic predicative sentence that contains no intensional terms, including modal operators and attitude verbs, is embedded. By the modifier 'in an extensional context,' I mean that the 'that'-clause itself is not included in the scope of any intensional terms either. Hence, by PS1, (2.3) follows. However, according to PR, (2.1) and (2.2) are true but (2.3) is false because it expresses a false identity, namely that (6p) is numerically identical to (7p). Recall, according to PR, (6p) and (7p) are structurally identical but numerically distinct SRPs. The semantic content of (2.3), thus, can be represented by:

(2.3p) $<<$ Mark Twain, being an author $>_{1},=$, $<$ Mark Twain, being an author $>_{2}>$

To derive (2.3), given (2.2), the second occurrence of 'Mark Twain' in (2.1) should be substituted with 'Samuel Clemens,' using (PS1). This use of (PS1) is acceptable because neither the 'that'-clause nor the sentence that contains the 'that'- 
clause include any intensional terms. Let me add that I am reading off the semantic content of (2.3), namely what is represented by (2.3p), from (2.3) itself because, first, (PS1) is a rule concerning the substitution of co-referential proper names, and second, Spencer does not discuss substitution of an individual for itself in a SRP. So, I apply (PS1) to the sentences and read off their semantic contents by assuming PR.

Note that the problem does not extend to 'that'-clauses such as 'that Santa Clause lives at the North Pole' and 'that Father Christmas lives at the North Pole,' unless PR accepts true simple atomic identity statements such as 'Santa Claus is Father Christmas ${ }^{, 37}$ and allows substitution of 'Father Christmas' for 'Santa Claus,' given that both proper names are genuinely empty. ${ }^{38}$

The puzzle is not necessarily based on the assumption that 'that'-clauses are singular terms referring to SRPs. ${ }^{39}$ It can be reformulated by means of other proposition-designating (singular) terms, for example, explicit proposition descriptions such as 'the proposition that p. ${ }^{40}$ The structure of the argument will remain intact.

37 That PR allows GPs does not, by itself, entail that the view allows true simple atomic GPs. Following a version of negative free logic, PR may consider all simple atomic GPs to be false.

38 Obviously, the problem does extend to 'that'-clauses that contain identity statements such as (8), i.e., 'Hesperus is Hesperus.' For example, given that the means of reference associated with 'Hesperus' is different from the means of reference associated with 'Phosphorus,' a similar argument may go like this:

(ARG 3)

(3.1) That Hesperus is Hesperus is (identical to) that Hesperus is Hesperus.

(3.2) Hesperus is Phosphorus.

(3.3) That Hesperus is Phosphorus is (identical to) that Hesperus is Hesperus.

Again, (3.1) and (3.2) are true. To derive (3.3), given (3.2), the second occurrence of 'Hesperus' in (3.1) should be substituted with 'Phosphorus.' Assuming (5) and that 'Hesperus is Hesperus' and 'Hesperus is Phosphorus' express structurally identical but numerically distinct SRPs, the semantic content of (ARG 3) can be represented by:

(ARG 3p)

(3.1p) $<<$ Hesperus, $=$, Hesperus $>_{1},=,<$ Hesperus, $=$, Hesperus $>_{1}>$.

(3.2p) $<<$ Hesperus, $=$, Hesperus $>_{1,2}$

(3.3p) $<<$ Hesperus, $=$, Hesperus $>_{1,2},=,<$ Hesperus, $=$, Hesperus $>_{1}>$.

Now, clearly (3.1p) and (3.2p) are true and (3.3p) is false.

For an argument against the thesis that 'that'-clauses are singular terms referring to propositions, see Rosefeldt, "That'-Clauses and Non-Nominal Quantification." Rosefeldt, however, accepts that proposition descriptions such as 'the proposition that p' are devices of singular reference to propositions. See Section V as well.

40 Here, and in similar places which I hope context clarifies, quotation should work like quasi-quotation. 
One might be suspicious of (ARG 2) and ARG (3) because in both arguments co-referential proper names are substituted within simple (predicative) 'that'-clauses which, in turn, are parts of identity statements. One might wonder if there is an argument to the same effect that only appeals to substitution of co-referential proper names within simple (predicative) sentences. There is such an argument; the puzzle, in a different formulation, shows that PR leads to the violation of the principle of substitutivity of co-referential proper names within simple (predicative) sentences. Consider:

(ARG 4)

(4.1) That Hesperus is Hesperus is (identical to) that Hesperus is Hesperus.

(4.2) Hesperus is such that (that it is Hesperus is (identical to) that Hesperus is Hesperus). (Lambda Introduction, 4.1.)

(4.3) Hesperus is Phosphorus.

(4.4) Phosphorus is such that (that it is Hesperus is (identical to) that Hesperus is Hesperus). (The principle of substitutivity of co-referential proper names within simple (predicative) sentences (PS2), the first occurrence of 'Hesperus' in 4.2 and 'Phosphorus' in 4.3.)

(4.5) That Phosphorus is Hesperus is (identical to) that Hesperus is Hesperus. (Lambda Elimination, 4.4.)

Once more, (4.1)-(4.3) are true. Let's represent their semantic contents respectively by:

(4.1p) $<<$ Hesperus, $=$, Hesperus $>_{1},=,<$ Hesperus, $=$, Hesperus $>_{1}>$

(4.2p) $<$ Hesperus, $\lambda \mathrm{x}\left[<<\mathrm{x},=\right.$, Hesperus $>_{1},=,<$ Hesperus, $=$, Hesperus $\left.>_{1}>\right]>$

$(4.3 p)<$ Hesperus, $=$, Hesperus $>_{1,2}$

The rule that legitimizes the move from (4.2) and (4.3) to (4.4) is the principle of substitutivity of co-referential proper names within simple (predicative) sentences (PS2). Let me formulate PS2 explicitly:

(PS2) If ' $a$ ' and ' $b$ ' are co-referential proper names and 'a' occurs in a simple (predicative) sentence, substituting one (or more) occurrence(s) of ' $a$ ' with ' $b$ ' results in a sentence with the same truth-value.

By 'a simple (predicative) sentence,' in PS2, I mean an atomic predicative sentence that contains no intensional terms, including modal operators and 
attitude verbs. In the language of classical first-order logic, a translation of PS2 is accepted as an axiom of identity and is essential to the concept of identity. To derive (4.4), substitution of co-referential proper names occurs in the subjectposition of a simple (predicative) sentence that has the following form: 'Hesperus is such-and-such.' The semantic content of (4.4) can be represented by:

(4.4p) $<$ Hesperus, $\lambda \mathrm{x}\left[<<\mathrm{x},=\right.$, Hesperus $>_{1},=,<$ Hesperus, $=$, Hesperus $\left.>_{1}>\right]>_{2}$

(4.4) contains three occurrences of 'Hesperus.' Index 1, in (4.4p), records the impact of the semantic means of reference associated with 'Hesperus' on the content of (4.4). Also, (4.4) contains one occurrence of 'Phosphorus.' Index 2 , in $(4.4 p)$, records the impact of the semantic means of reference associated with 'Phosphorus' on the content of (4.4).

By the rule of Lambda Elimination, (4.5) follows from (4.4). However, to repeat, given PR and that the means of reference associated with 'Hesperus' is different from the means of reference associated with 'Phosphorus,' it follows that (4.5) is false. The semantic content of (4.5) can be represented by:

$(4.5 p)<<$ Hesperus, $=$, Hesperus $>_{2,1},=,<$ Hesperus, $=$, Hesperus $>_{1}>$.

I have represented the semantic content of:

(4.5.1) That Phosphorus is Hesperus.

by:

(4.5.1p) $<$ Hesperus, $=$, Hesperus $>_{2,1}$

and the semantic content of:

(4.5.2) That Hesperus is Hesperus.

by:

$(4.5 .2 \mathrm{p})<$ Hesperus, $=$, Hesperus $_{1}$

(4.5) includes (4.5.1) and (4.5.2) and (4.5p) includes (4.5.1p) and (4.5.2p). The indices, namely 2,1 , in $(4.5 .1 \mathrm{p})$, can be interpreted as recording the order of occurrences of 'Phosphorus' and 'Hesperus' in (4.5.1), and, thus, in (4.5). But this is not crucial for my argument. Again, I am applying (PS2) to the sentences and read off their contents by assuming PR. So long as the semantic means of reference by which 'Phosphorus' refers to Venus is different from the semantic means of reference by which 'Hesperus' refers to Venus, (4.5.1p) 
and (4.5.2p) will be non-identical and thus (4.5p), and hence (4.5), will be false. $^{41}$

One might attempt to block (ARG 4) by reading off the content of (4.5) as represented by $\left(4.5 p^{\prime}\right)$, instead of $(4.5 p)$ :

$$
\left(4.5 p^{\prime}\right)<<\text { Hesperus, }=\text {, Hesperus }>_{2,1},=,<\text { Hesperus, }=, \text { Hesperus }>_{2,1}>
$$

Indices of the two ingredient propositions in (4.5p') are the same. For my purposes, their order is not at stake, they could be put as '1,2.' Spencer has not explained how the index of the outer-most proposition should be distributed over the ingredient propositions; in fact, the issue has not been raised in the first place. It is noteworthy that this problem does not arise in (ARG 2) and (ARG 3) because substitution of co-referential proper names is directly done into the 'that'clause occurring in the identity statement. The point of (4.5p') is to make the identity between two ingredient propositions, expressed by (4.5), come out true. I will address this line of response in the following section (see, particularly, the last part).

\section{Replies and Rebuttals}

In reply, the proponent of PR has two general strategies: First, to accept that (ARG 2)-(ARG 4) show that PR leads to the violation of PS1 or PS2 and

41 It is not the case that all instances of(PS2) are problematic for PR. For example, consider:

(ARG 4')

$\left(4^{\prime} .1\right)$ Mark Twain is an author.

$\left(4^{\prime} .2\right)$ Mark Twain is Samuel Clemens.

(4'.3) Samuel Clemens is an author.

The validity of (ARG 4'), given PR, can be explained by structural identity of the semantic content of $\left(4^{\prime} .1\right)$ and that of $\left(4^{\prime} .3\right)$. Let us represent the content of (ARG $4^{\prime}$ ) by:

(ARG 4'p)

$\left(4^{\prime} .1 \mathrm{p}\right)<$ Mark Twain, being an author $>_{1}$

$\left(4^{\prime} .2 \mathrm{p}\right)<$ Mark Twain, $=$, Mark Twain $>_{1,2}$

$\left(4^{\prime} .3 p\right)<$ Mark Twain, being an author $>_{2}$

(PS2) legitimizes substitution of co-referential proper names within simple (predicative) sentences. In arguments similar to (ARG 4'), application of (PS2) cannot affect the validity of the argument since what matters for the truth of $\left(4^{\prime} .1\right)$ is the semantic reference of 'Mark Twain,' not the semantic means of reference associated with 'Mark Twain,' and whether that individual has the property of being an author. (PS2) presupposes the sameness of the semantic reference of the proper names involved in the argument and, thus, assuming that there is no other difference between the conclusion and first premise, it follows that if the premise is true, the conclusion will be. 
embrace this consequence. Second, to try to move one step further from NR, and revise PR more radically, such that (ARG 2)-(ARG 4) no longer show that PR leads to the violation of PS1 or PS2.

The first strategy does not take PS1 and PS2 to be obvious truths. Accordingly, one might treat 'that'-clauses as 'intensional contexts' in which co-referential proper names may not be substitutable salve veritate. Given PR, this reply suggests, (ARG 2)-(ARG 4) are not valid, and therefore not sound. If $\mathrm{PR}$ is true, then co-referential singular terms may not be substitutable salve veritate and, hence, neither PS1 nor PS2 is necessarily truth-preserving. This is not an exception, the reply continues, as there are many alleged counterexamples to the principle of substitutivity of co-referential singular terms in intensional and hyperintensional contexts. Similarly, here, substitutivity of co-referential singular terms is not allowed and, thus, (ARG 2)-(ARG 4) are not valid. Therefore, there is no objection to PR.

This reply seems to push PR toward Fregeanism, so far as 'that'-clauses are at stake. The Russellian would not find this strategy promising for three reasons. First, neither PS1 nor PS2 is the principle of substitutivity of co-referential singular terms salve veritate; rather, they are more specific principles. PS1 is the principle of substitutivity of co-referential proper names within simple (predicative) 'that'-clauses, in an extensional context, and PS2 is the principle of substitutivity of co-referential proper names in simple (predicative) sentences. Simple (predicative) 'that'-clauses and sentences contain no intensional terms, including modal operators and attitude verbs. Thus, intensional and hyperintensional contexts that provide counterexamples to the principle of substitutivity of co-referential proper names are beside the point. Second, given that proper names are rigid designators, substitutivity of co-referential proper names, even in the context of modal operators and attitude verbs, is central to the Russellian views. In fact, different pragmatic and psychological explanations devised within the Russellian camp are intended to explain away, among other things, the intuitions of substitution failure (within simple (predicative) 'that'-clauses and sentences) when rigid designators are involved. ${ }^{42}$ Third, given that appropriate forms of Lambda Introduction and abstraction are available, (ARG 4) shows that PR leads to the violation of PS2, which is a translation of an axiom of identity. Even if the Russellian is willing to withhold assent to PS1, or disputes its application in (ARG 2) and (ARG 3), it is not clear how PS2 can be compromised, given NR.

The second strategy involves moving one step further from NR and revising PR more radically to save PS1 and PS2. Given that Millianism with regard to proper names and (simple) predicates, namely (1) and (2), and Russellianism

42 See, for instance, Salmon, Frege's Puzzle, Soames, "Direct Reference, Propositional Attitudes, and Semantic Content," Saul, "Substitution and Simple Sentences," and Braun "Understanding Belief Reports." 
with regard to simple atomic sentences, namely (3), are central to NR and PR (PR itself accepts all principles of NR except (4)), the most natural way to develop this line of reply is to disavow (5). Recall:

(5) The semantic content of a simple (predicative) 'that'-clause ([that $\mathrm{N}$ is $\mathrm{F}\rceil$ ) is the SRP semantically expressed by the simple atomic sentence ( $[\mathrm{N}$ is $\mathrm{F}\rceil$ ) embedded in the 'that'-clause.

Rejecting (5) requires an alternative semantics for a simple (predicative) 'that'-clause ([that $\mathrm{N}$ is $\mathrm{F}\rceil$ ). I will discuss two possibilities.

First, if, according to this alternative semantics, (i) $\lceil\mathrm{N}$ is $\mathrm{F}\rceil$ satisfies semantic innocence, that is $\lceil\mathrm{N}$ is $\mathrm{F}\rceil$ makes its standard contribution to the semantic con-

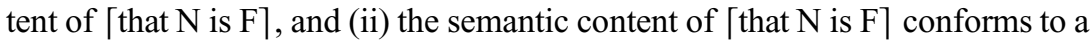
principle of compositionality of semantic content, according to which if the content of $\lceil$ that $\mathrm{S}\rceil$ and that of $\lceil$ that $\mathrm{R}\rceil$ only differ in one constituent, then they are not identical, then it can be shown that the puzzle will resurge.

Let me illustrate. François Recanati ${ }^{43}$ provides an alternative semantics for 'that'-clauses, according to which they are quantified noun phrases whose semantic contents are higher-order properties, or relations. For example, the semantic content of 'that grass is green,' according to Recanati, can be represented by:

\section{$\lambda X \lambda x[(\exists p: \operatorname{TRUE}(p)$ iff GREEN (grass)) $X(x, p)]$}

' $\mathrm{p}$ ' is an objectual variable ranging over truth-evaluable entities. ' $\mathrm{X}$ ' ranges over first-order relations, e.g., BELIEVES, that are the semantic contents of propositional attitude verbs, e.g., 'believes.' And 'x' ranges over individuals, e.g., John. ${ }^{44}$

Accordingly, the semantic content of [that $\mathrm{N}$ is $\mathrm{F}$ ] is not the SRP semantically expressed by the simple atomic sentence ( $[\mathrm{N}$ is $\mathrm{F}\rceil$ ) embedded in the 'that'clause. Hence, (5) no longer holds. Now, recall:

(6) Mark Twain is an author.

(7) Samuel Clemens is an author.

43 Recanati, “"That'-Clauses as Existential Quantifiers."

44 Thus, for example, the semantic content of 'believes that grass is green' is the result of applying the above higher-order property to BELIEVES, namely:

$\lambda x[(\exists \mathrm{p}$ : TRUE( $\mathrm{p})$ iff GREEN (grass)) BELIEVES $(\mathrm{x}, \mathrm{p})]$

And the semantic content of 'John believes that grass is green,' in turn, is the result of applying the above first-order property to John, namely:

[(ヨp: TRUE( $\mathrm{p})$ iff GREEN (grass))] BELIEVES (John, p)

This reads that "for some $\mathrm{p}$ such that $\mathrm{p}$ is true iff grass is green, John believes p" (Recanati, “"That'-Clauses as Existential Quantifiers,” 231). 
Again, given PR, suppose that (6) and (7) express structurally identical but numerically distinct SRPs, namely:

(6p) $<$ Mark Twain, being an author $>_{1}$

(7p) $<$ Mark Twain, being an author $>_{2}$

Also, recall:

(6') That Mark Twain is an author

(7') That Samuel Clemens is an author

Given Recanati's view and semantic innocence for (6) and (7), that is if (6) and (7) make their standard contribution, namely (6p) and (7p), to the semantic content of $\left(6^{\prime}\right)$ and that of $\left(7^{\prime}\right)$, the semantic content of $\left(6^{\prime}\right)$ and that of $\left(7^{\prime}\right)$ can be represented by:

$\left(6^{\prime \prime}\right) \lambda \mathrm{X} \lambda \mathrm{x}\left[\left(\exists \mathrm{p}: \operatorname{TRUE}(\mathrm{p})\right.\right.$ iff $<$ Mark Twain, being an author $\left.\left.>_{1}\right) \mathrm{X}(\mathrm{x}, \mathrm{p})\right]$

$\left(7^{\prime \prime}\right) \lambda X \lambda x\left[\left(\exists \mathrm{p}: \operatorname{TRUE}(\mathrm{p})\right.\right.$ iff $<$ Mark Twain, being an author $\left.\left.>_{2}\right) \mathrm{X}(\mathrm{x}, \mathrm{p})\right]$

Assuming a principle of compositionality of semantic content, according to which if properties $\mathrm{X}$ and $\mathrm{Y}$ only differ in one constituent then they are not identical, it follows that the property represented by $\left(6^{\prime \prime}\right)$ is not identical to the property represented by $\left(7^{\prime \prime}\right)$ because they differ in one constituent, namely (6p) and (7p) occurring on the right-hand side of the biconditionals in $\left(6^{\prime \prime}\right)$ and $\left(7^{\prime \prime}\right)$ correspondingly. This validates a new version of (ARG 2), namely (ARG 2'), which has the same formulation, that is $\left(2^{\prime} .1\right),\left(2^{\prime} .2\right)$, and $\left(2^{\prime} .3\right)$ are $(2.1)$, (2.2), and (2.3) respectively, but different content. The content of (ARG 2') can be represented by:

\section{(ARG 2'p)}

$\left(2^{\prime} .1 \mathrm{p}\right)<\lambda \mathrm{X} \lambda \mathrm{x}\left[\left(\exists \mathrm{p}: \mathrm{TRUE}(\mathrm{p})\right.\right.$ iff $<$ Mark Twain, being an author $\left.>_{1}\right)$ $\mathrm{X}(\mathrm{x}, \mathrm{p})],=$, $\lambda X \lambda x\left[\left(\exists \mathrm{p}: \operatorname{TRUE}(\mathrm{p})\right.\right.$ iff $<$ Mark Twain, being an author $\left.\left.>_{1}\right) \mathrm{X}(\mathrm{x}, \mathrm{p})\right]>$

$\left(2^{\prime} .2 \mathrm{p}\right)<$ Mark Twain, $=$, Mark Twain $>_{1,2}$

$\left(2^{\prime} .3 p\right)<\lambda X \lambda x\left[\left(\exists \mathrm{p}:\right.\right.$ TRUE $(\mathrm{p})$ iff $<$ Mark Twain, being an author $\left.>_{1}\right)$ $\mathrm{X}(\mathrm{x}, \mathrm{p})],=$, $\lambda \mathrm{X} \lambda \mathrm{x}\left[\left(\exists \mathrm{p}: \operatorname{TRUE}(\mathrm{p})\right.\right.$ iff $<$ Mark Twain, being an author $\left.\left.>_{2}\right) \mathrm{X}(\mathrm{x}, \mathrm{p})\right]>$

Thus, the puzzle resurges. Again, I am reading off the semantic content of each line, namely (2.1), (2.2), and (2.3), from the line itself, assuming PR and 
Recanati's semantics for 'that'-clauses. In particular, $(2$ '.3p) is the semantic content of $\left(2^{\prime} .3\right)$, which is the same as (2.3). I have not recovered $\left(2^{\prime} .3 \mathrm{p}\right)$ from $\left(2^{\prime} .1 p\right)$ and $\left(2^{\prime} .2 p\right)$. To repeat, Spencer does not discuss substitution of an individual for itself in a SRP. According to PR, a SRP may change its identity by substituting an individual for itself if the names referring to the individual in the two cases are associated with different semantic means of reference. Given the above-mentioned principle of compositionality of semantic content, the same result follows for properties containing SRPs. According to this proposal, thus, Spencer's view has the conclusion that the semantic content of (6') is distinct from the semantic content of $\left(7^{\prime}\right)$ and hence $\left(2^{\prime} .3 p\right)$ is false. This brings us to the second option for the second strategy.

Second, the proponent of PR might consider a semantics for 'that'-clauses, according to which though (6) and (7) express distinct SRPs, namely (6p) and $(7 \mathrm{p})$, the corresponding 'that'-clauses, namely $\left(6^{\prime}\right)$ and $\left(7^{\prime}\right)$, have the same semantic content. To achieve this goal, one might reject semantic innocence for (6) and (7) or the aforementioned principle of compositionality of semantic content. Either way, (5), in the characterization of NR, needs to be revised. For example, one might consider a standard Russellian semantics for 'that'-clauses, according to which they are singular terms referring to (Russellian) propositions, 'under a uniqueness condition.' That is to substitute (5) with (5'):

(5') The SRP semantically referred to by a 'that'-clause ([that N is F $\rceil$ ) is uniquely determined by the semantic content of the proper name and that of the simple predicate (Uniqueness for 'that'-clauses).

$\left(5^{\prime}\right)$, in effect, cancels out the role of semantic means of reference in the individuation of the semantic contents of 'that'-clauses. Therefore, though (6) and (7) semantically express structurally identical but numerically distinct SRPs, namely (6p) and (7p), the corresponding 'that'-clauses, namely $\left(6^{\prime}\right)$ and $\left(7^{\prime}\right)$, semantically refer to one and the same standard SRP, which can be represented by:

$(6 / 7 \mathrm{p})<$ Mark Twain, being an author $>$

(6/7p) has no indices. According to this proposal, (ARG 2)-(ARG 4) can be blocked because the last line of each of these arguments has a true identity statement that includes two 'that'-clauses that refer to one and the same standard SRP. And this is obvious if one removes the indices from (2.3p), (3.3p), and (4.5p) or uses a technique to assign the same indices to the ingredient propositions involved therein, as was suggested above in (4.5p'), for example.

The above reply, however, is ad hoc, first, and undermines a main motivation for PR, second. It is not clear, in a non-ad hoc way, why semantic means of reference are allowed to contribute to the individuation of SRPs where they are expressed by sentences but the very same semantic means of reference are not 
allowed to do so where SRPs are referred to by 'that'-clauses. It is as though when one attempts to entertain a SRP via expressing it by a sentence, one succeeds and can correctly comprehend the proposition itself, but when one attempts to entertain the very same proposition via referring to it by a 'that'clause, which contains the very same sentence that expresses the proposition, one fails and cannot comprehend that proposition. (Instead, perhaps, one entertains the standard SRP that represents the class of all structurally identical but numerically distinct SRPs (according to PR) that has the proposition in question as a member.) The least is that there is an explanatory gap here. Furthermore, PR overgenerates, as it were, Russellian propositions by introducing structurally identical but numerically distinct SRPs to solve Frege's Puzzle of Identity and Frege's Puzzle of Cognitive Value, among other problems. Revising the semantics of 'that'-clauses such that $\left(6^{\prime}\right)$ and $\left(7^{\prime}\right)$, for instance, find the same semantic content brings PR back to the stage in which some Fregean-style objections to NR can be levelled against PR.

For example, consider:

\section{(ARG 5)}

(5.1) Hammurabi believes that Hesperus is Hesperus.

(5.2) Hesperus is Phosphorus.

(5.3) Hammurabi believes that Hesperus is Phosphorus.

According to NR, (ARG 5) is sound and the intuition that Hammurabi does not believe that Hesperus is Phosphorus, assuming that he sincerely assents that Hesperus is not Phosphorus, should be explained away by the pragmatics of belief reports or the psychology of belief states, among other ways. If a revised version of PR takes

(8') That Hesperus is Hesperus

(9') That Hesperus is Phosphorus

to have the same semantic content (even if the semantic means of reference associated with 'Hesperus' is different from the semantic means of reference associated with 'Phosphorus'), then (ARG 5) would be sound. This, in turn, would regenerate the counterintuitive consequence that Hammurabi does believe that Hesperus is Phosphorus, namely (5.3). PR, however, was designed to allow (8) and (9), namely:

(8) Hesperus is Hesperus.

(9) Hesperus is Phosphorus. 
express distinct SRPs with different functions, and, thus, different cognitive profiles (see Section 2). The above reply, in effect, makes these distinct SRPs useless for the semantics of belief reports (and propositional attitude verbs in general). Consequently, to explain away the intuition that Hammurabi does not believe that Hesperus is Phosphorus, the proponent of PR, like the proponent of NR, would again need to appeal to the Russellian pragmatic or psychological explanations, or something to the same effect. Then, one might wonder why one should overgenerate Russellian propositions, as PR suggests, in the first place, if at the end of the day the same Russellian explanations are needed.

\section{Conclusion}

PR departs from NR by rejecting (4) or (Uniqueness). However, the view attempts to remain faithful to the core of NR and find some 'semantic' solutions to or explanations for some significant problems, puzzles, and odd consequences that NR faces. Admittedly, PR's semantic treatment of these issues is novel. However, if (ARG 2)-(ARG 4) hold, then PR faces a semantic puzzle that the classic versions of NR do not: it leads to the violation of the principle of substitutivity of co-referential proper names within simple (predicative) 'that'-clauses (PS1) and/or the principle of substitutivity of co-referential proper names within simple (predicative) sentences (PS2). To avoid the puzzle, the proponent of PR might reject PS1 and PS2, or their applications in (ARG 2)-(ARG 4). Accordingly, one might treat 'that'-clauses as 'intensional contexts' in which co-referential proper names may not be substitutable salve veritate. This reply seems to push PR toward Fregeanism, so far as 'that'-clauses are at stake. The Russellian would not find this reply promising for different reasons, e.g., the consensus to preserve both PS1 and PS2 not only in the extensional contexts but also in the context of modal operators and attitude verbs. Alternatively, to save PS1 and PS2, the proponent of PR might try to revise the semantics of 'that'-clauses by further revising NR (and PR). I considered two such possible revisions and showed that either the puzzle will resurge or the attempted solution is ad hoc and undermines a main motivation for PR. Either way, PR needs to depart from NR more radically. It will remain to be seen how the proponent of PR can best react to the puzzle without compromising her core Russellian commitments.

\section{Acknowledgements}

I would like to thank Hamid Vahid, for commenting on part of the material presented here, Laleh Ghadakpour, for providing me with the French translation of the abstract, Joshua Spencer, for helping me with the formulation of (ARG 4), and Faraz Ghalbi, for reading and discussing an earlier draft of this work. I am also indebted to three anonymous referees of this journal for their instructive comments, criticisms, and suggestions. This research is partly done within the research programme Representation and Reality: Historical and Contemporary Perspectives on the Aristotelian Tradition (funded by Riksbankens Jubileumsfond). 


\section{References}

Adams, Fred, and Gary Fuller

2007 "Empty Names and Pragmatic Implicatures." Canadian Journal of Philosophy 37(3): 449-462.

Adams, Fred, and Laura A. Dietrich

2004 "What's in a(n Empty) Name?" Pacific Philosophical Quarterly 85(2): 125-148.

Adams, Fred, and Robert Stecker

1994 "Vacuous Singular Terms." Mind \& Language 9(4): 387-401.

Baker, Lynne R.

2000 Persons and Bodies. Cambridge: Cambridge University Press.

Braun, David

2005 "Empty Names, Fictional Names, Mythical Names." Noûs 39(4): 569-631.

Braun, David

2002 "Cognitive Significance, Attitude Ascriptions, and Ways of Believing." Philosophical Studies 108(1-2): 65-81.

Braun, David

2001a "Russellianism and Explanation." Philosophical Perspectives 15(1): 253-289.

Braun, David

2001b "Russellianism and Predication." Philosophical Studies 105(1): 59-105.

Braun, David

1998 "Understanding Belief Reports." The Philosophical Review 107(4): $555-595$.

Everett, Anthony

2013 The Nonexistent. Oxford: Oxford University Press.

Everett, Anthony

2003 “Empty Names and 'Gappy’ Propositions.” Philosophical Studies 116 (1): $1-36$.

Fine, Kit

2007 Semantic Relationalism. Malden, MA: Wiley-Blackwell.

Hanks, Peter

2015 Propositional Content. Oxford: Oxford University Press.

Hanks, Peter

2011 “Structured Propositions as Types.” Mind 120(477): 11-52.

Hodgson, Thomas

2020 "The Structure of Content Is Not Transparent." Topoi 39(2): 425-437.

Hodgson, Thomas

2013 "Why We Should Not Identify Sentence Structure with Propositional Structure." Canadian Journal of Philosophy 43(5-6): 612-633. 
King, Jeffrey C.

2007 The Nature and Structure of Content. Oxford: Oxford University Press. King, Jeffrey C.

2002 "Designating propositions." The Philosophical Review 111(3): 341371.

King, Jeffrey C., Scott Soames, and Jeff Speaks

2014 New Thinking about Propositions. Oxford: Oxford University Press. Mousavian, Seyed N.

2015 "Pragmatics of No Reference." Mind \& Language 30(1): 95-116.

Mousavian, Seyed N.

2011 “Gappy Propositions?" Canadian Journal of Philosophy 41(1): $125-158$.

Noonan, Harold

1993 “Constitution Is Identity.” Mind 102(405): 133-146.

Recanati, François

2004 “That'-Clauses as Existential Quantifiers." Analysis 64(3): 229-235.

Rosefeldt, Tobias

2008 “"That'-Clauses and Non-Nominal Quantification." Philosophical Studies 137(3): 301-333.

Salmon, Nathan

2005 Metaphysics, Mathematics, and Meaning. Oxford: Oxford University Press.

Salmon, Nathan

1986 Frege's Puzzle. Cambridge, MA: MIT Press.

Saul, Jennifer M.

1997 "Substitution and Simple Sentences." Analysis 57(2): 102-108.

Soames, Scott

2019 “Propositions as Cognitive Acts." Synthese 196(4): 1369-1383.

Soames, Scott

2015 Rethinking Language, Mind, and Meaning. Princeton: Princeton University Press.

Soames, Scott

2014 "Cognitive Propositions," in New Thinking about Propositions, edited by Jeffrey C. King, Scott Soames, and Jeff Speaks. Oxford: Oxford University Press, pp. 91-126.

Soames, Scott

2002 Beyond Rigidity. New York: Oxford University Press.

Soames, Scott

1987 "Direct Reference, Propositional Attitudes, and Semantic Content." Philosophical Topics 15(1): 47-87.

Spencer, Joshua

Forthcoming "Plenitudinous Russellianism," in Routledge Handbook of Propositions, edited by Chris Tillman. New York, NY: Routledge, Chapter 21. 


\section{Dialogue}

Spencer, Joshua

2016 "The Problem of Empty Names and Russellian Plenitude." Canadian Journal of Philosophy 46(3): 387-404.

Spencer, Joshua

2014 “Unnecessary Existents." Canadian Journal of Philosophy 43(5-6): 766-775.

Williamson, Timothy

2013 Modal Logic as Metaphysics. Oxford: Oxford University Press.

Williamson, Timothy

2002 "Necessary Existents," in Logic, Thought, and Language, edited by Anthony O'Hear. Cambridge: Cambridge University Press, pp. 233251. 